\title{
Pervaporation Separation of Benzene/Cyclohexane Mixtures through Polyamide-Polyether Block Copolymer Membranes
}

\author{
Keisuke Tsubouchi and Masakazu Yoshikawa
}

Department of Polymer Science and Engineering, Kyoto Institute of Technology, Matsugasaki, Kyoto 606-8585, Japan

\begin{abstract}
Pervaporation separation of benzene/cyclohexane mixtures through polyamide-polyether block copolymer membranes was studied. Benzene was permeated in preference to cyclohexane. Pervaporation performance was greatly dependent not only on polyamide/polyether composition but also on kinds of blocks, polyamide and polyether.
\end{abstract}

Key words : pervaporation/polyamide-polyether block copolymer/benzene/cyclohexane/permselectivity

\section{Introduction}

Membrane separation processes have been attracting attention as one of promising energy-saving separation techniques. In the separation of liquid mixtures, especially in the separation of azeotropic mixtures, heatsensitive compounds, and organic mixtures having close boiling points, pervaporation is expected to bring into full play partly because pervaporation is independent of their osmotic pressures.

The separation of olefins/paraffins or aromatics/aliphatics mixtures with synthetic polymeric membranes is an interesting subjects in petrochemical industries. To this end, pervaporation of benzene/cyclohexane mixtures were investigated in the present study.

Not a few articles dealt with pervapora- tion of benzene/cyclohexane mixtures ${ }^{1 \sim 26)}$. The authors adopted polyamide 6 as a starting material for membrane polymer ${ }^{20,22}$ because of its excellent strength and commercial availability. Poly(ethyl methacrylate $)^{20)}$ or oligooxyethylenes ${ }^{22)}$ were introduced onto polyamide 6 and pervaporation separation of benzene/cyclohexane through these membranes thus modified was investigated.

In the present article, the pervaporation separation of benzene/cyclohexane mixtures with the membranes from multi block co- $^{-}$ polymers, consisting of polyamide and polyether, is described.

\section{Experimental}

\section{1 Membrane Preparation}

Four kinds of membrane materials used 


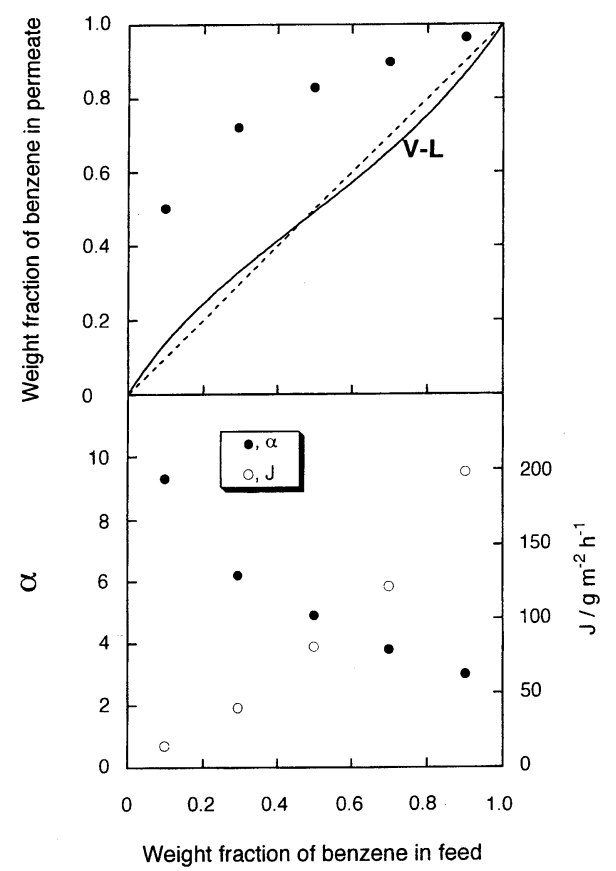

Fig. 1 Effect of feed composition on pervaporation, separation factor, $\alpha$, and flux, $\mathrm{J}$, of banzene/cyclohexane mixtures through PA12/POE (3/1) membrane. (Operating temperature, $50^{\circ} \mathrm{C}$; downstream pressure, ca. $267 \mathrm{~Pa} \quad(2.0$ $\mathrm{mmHg})$.)

in the present study are as follows : PA12/ POE (3/1), which consists of polyamide 12 (PA12) and polyoxyethylene (POE) blocks, of which weight ratio of blocks being around $3 / 1$; PA12/POE (1/1), whose ratio being $1 / 1$; PA12/PTM (5/1), which consists of PA12 and polyoxytetramethylene (PTM), of which weight ratio being 5/1; PA6/POE (1/1), which consists of polyamide 6 (PA6) and POE, whose weight ratio being $1 / 1$. In every material, the molecular weight of shorter block was in the range of 1,000. All membranes were prepared by melt method. The thickness of membrane was around $100 \mu \mathrm{m}$.

\section{2 Pervaporation}

Permeation of the benzene/cyclohexane mixture was performed by an ordinary pervaporation technique ${ }^{27)}$. The membrane area in contact with the liquid feed was 17.3 $\mathrm{cm}^{2}$. The downstream pressure applied was kept to be around $267 \mathrm{~Pa}(2.0 \mathrm{mmHg})$. Pervaporation experiments were carried out at the constant temperature of $50^{\circ} \mathrm{C}$.

Separation analysis was carried out on a Shimadzu GC-8APT gas chromatograph equipped with a $3.0 \mathrm{~m}$ long column packed with polyethyleneglycol 6000 (Shimalite TPA).

The separation factor, $\alpha$, is defined as

$$
\begin{aligned}
\alpha= & \left(\mathrm{Y}_{\text {benzene }} / \mathrm{Y}_{\text {cyclohexane }}\right) / \\
& \left(\mathrm{X}_{\text {benzene }} / \mathrm{X}_{\text {cyclohexane }}\right)
\end{aligned}
$$

where the $\mathrm{Y}_{i} \mathrm{~S}$ are the weight fractions in the permeate and $X_{i} \mathrm{~S}$ are those in the feed, respectively.

\section{Results and Discussion}

\section{1 Effect of Polyamide/Polyether Com- position}

Pervaporation results through the membranes, having different polyamide/polyether composition, are shown in Figs. 1 and 2. Vapor-liquid equilibrium curve for benzene/cyclohexane mixtures at $50^{\circ} \mathrm{C}$ (solid curve ${ }^{28)}$ and diagonal line (dashed line) are given in all figures. These two membranes consist of polyamide 12 (PA12) and polyoxyethylene (POE) and have different polyamide/polyether compositions. As can be seen, the increase in polyether content in the membrane led to the increase in flux, while the permselectivity toward benzene was decreased with the polyether content. This can be explained as follows : the in- 


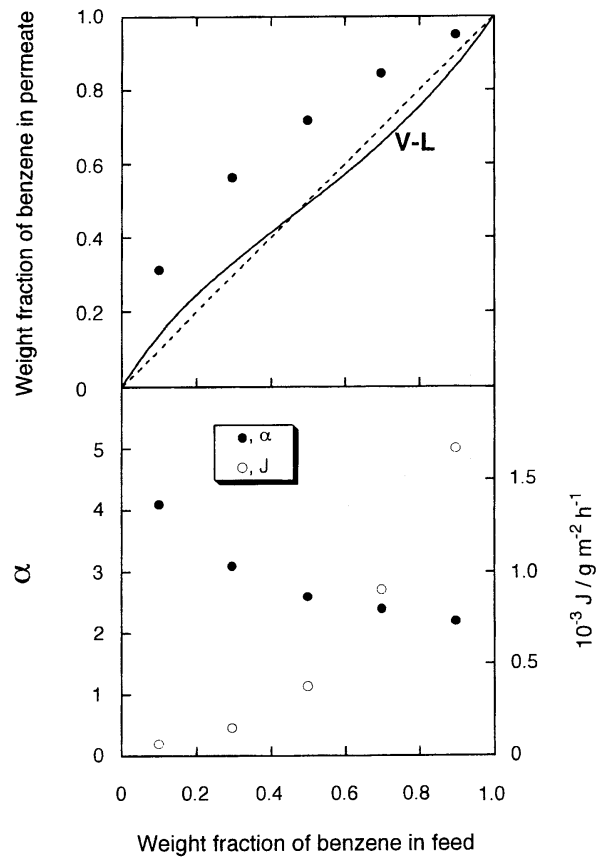

Fig. 2 Effect of feed composition on pervaporation, separation factor, $\alpha$, and flux, $J$, of banzene/cyclohexane mixtures through PA12/POE (1/1) membrane. (Operating temperature, $50^{\circ} \mathrm{C}$; downstream pressure, ca. $267 \mathrm{~Pa} \quad(2.0$ $\mathrm{mmHg}$ ).)

crease in polyoxyethylene content induced the increase in affinity of membrane toward benzene. This increase in affinity toward benzene caused the membrane swelling. Flux values for PA12/POE (1/1) membrane were, as a result, higher than those for PA 12/POE (3/1) membrane, while permselectivities toward benzene for the latter were higher than the former.

\section{2 Effect of Polyether Unit}

In the present section, PA12 was adopted as a polyamide unit and the effect of polyether unit on pervaporation performance was investigated by using polyoxyethylene or polyoxytetramethylene as a polyether unit.

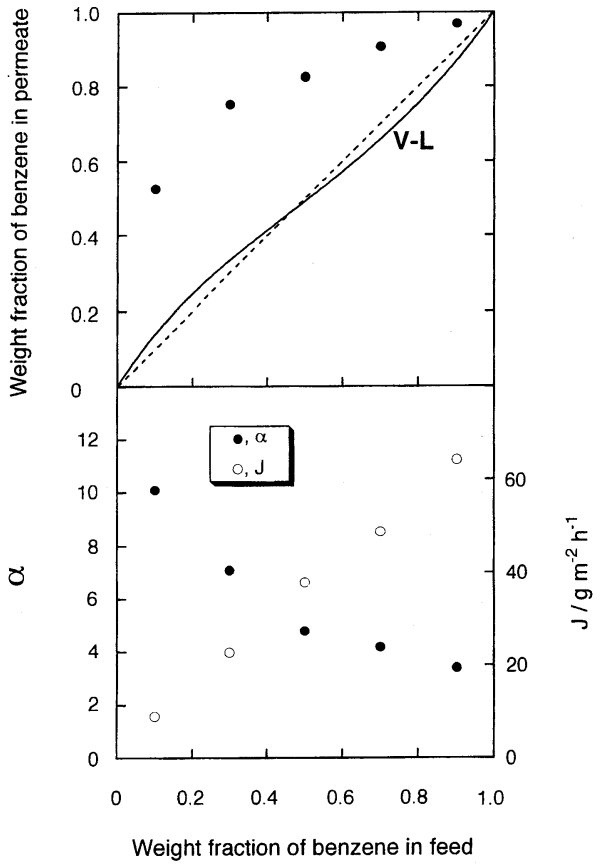

Fig. 3 Effect of feed composition on pervaporation, separation factor, $\alpha$, and flux, $\mathrm{J}$, of banzene/cyclohexane mixtures through PA12/PTM (5/1) membrane. (Operating temperature, $50^{\circ} \mathrm{C}$; downstream pressure, ca. $267 \mathrm{~Pa} \quad(2.0$ $\mathrm{mmHg})$.)

The membrane shown in Fig. 1 consisted of PA12 and POE and the membrane given in Fig. 3 was prepared from PA12 and PTM. Even though every unit consisting each membrane has a slight difference, it was judged that it is possible to deduce the effect of polyether unit on pervaporation of benzene/cyclohexane mixtures. Comparing with polarities of polyether unit, that for POE is higher than that for PTM. From this the affinity toward benzene for PA12/POE (3/1) membrane might be higher than that for PA12/ PTM (5/1) one. From this, PA12/POE (3/1) membrane should be swollen more than PA $12 /$ PTM $(5 / 1)$ one. It can be expected the former gave higher flux than the latter, 


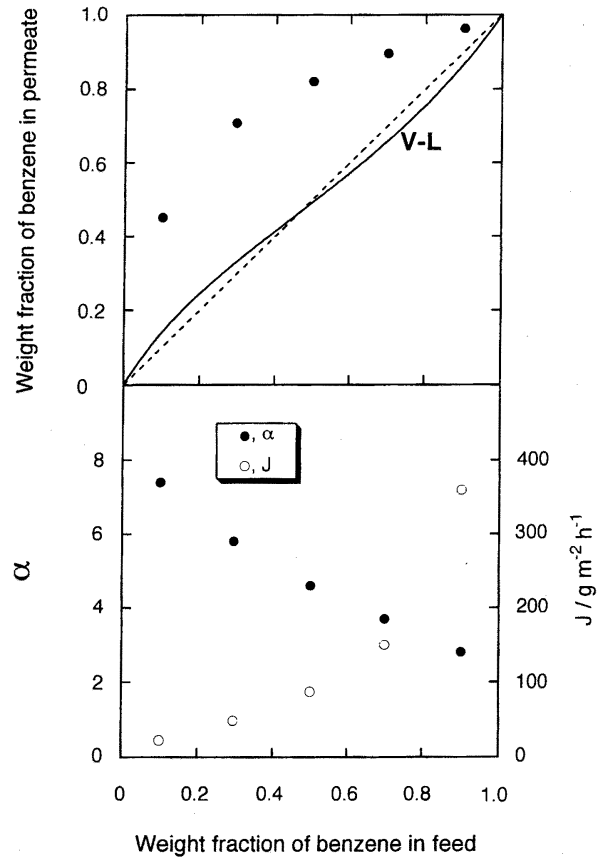

Fig. 4 Effect of feed composition on pervaporation, separation factor, $\alpha$, and flux, $\mathrm{J}$, of banzene/cyclohexane mixtures through PA6/POE (1/1) membrane. (Operating temperature, $50^{\circ} \mathrm{C}$; downstream pressure, ca. $267 \mathrm{~Pa} \quad(2.0$ $\mathrm{mmHg})$.)

while pemselectivities given by the latter were higher than those by the former. The expectation for flux was confirmed by the experiments, of which results are given in Figs. 1 and 3, while these two kinds of membranes gave similar permselectivities. Chain flexibility is one of factors to reign permselectivity. PTM segment might be more flexible than POE one from their glass transition temperatures ${ }^{29)}$. Effect by swelling and that by chain flexibility are compensated, and as a result similar permselectivities were observed.

\section{3 Effect of Polyamide Unit}

Here, polyether unit was fixed by using polyoxyethylene and effect of the kind of polyamide was investigated by adopting PA 12 (Fig. 2) and PA6 (Fig. 4). From Figs. 2 and 4, the change from PA12 to PA6 led not only to the enhancement of permselectivity but also to the suppression of flux value. This is thought to be due to the difference in physical properties of polyamide unit. That is, the presence of PA6 is more effective to suppress the membrane swelling by benzene than that of PA12.

\section{Conclusions}

Following conclusions can be drawn from the present study :

1. Polyamide-polyether block copolymer membranes showed permselectivity toward benzene in pervaporation of benzene/cyclohexane mixtures.

2. Pervaporation performance, such as permselectivity and flux, is greatly dependent on polymer composition and difference of constituent blocks.

3. Polyamide-polyether block copolymer membranes studied in the present study has a potential to separate aromatics/aliphatics mixture in petroleum refinery processes.

Acknowledgement The authors are grateful to Elf Atochem Japan for their kindly providing membrane materials.

\section{References}

1) Kucharski M, Stelmaszek J : Int. Chem. Eng., 7 618-622 (1967)

2) Huang R Y M, Lin V J C : J. Appl. Polym. Sci., 12 2615-2631 (1968)

3) McCandless F P : Ind. Eng. Chem. Process Des. Develop., 12 354-359 (1973)

4) McCandless F P, Alzheimer D P, Hartman R 
B : Ind. Eng. Chem. Process Des. Develop., 13 310-312 (1974)

5) Cabasso I, Jagur-Grodzinski J : J. Appl. Polym. Sci., 18 2117-2136 (1974)

6) Cabasso I, Jagur-Grodzinski J, Vofsi D : J. Appl. Polym. Sci., 18 2137-2147 (1974)

7) Yoshimasu $S$, Nomura H, Komiya K, Okano T, Shinohara I : Nippon Kagaku Kaishi, 17851791 (1980)

8) Terada J, Hohjoh T, Yoshimasu S, Ikemi M, Shinohara I : Polymer J., 14 347-353 (1982)

9) Cabasso I : Ind. Eng. Chem. Prod. Res. Dev., 22 313-319 (1983)

10) Acharya H R, Stern S A, Liu Z Z, Cabasso I : J. Membrane Sci., 37 205-232 (1988)

11) Park J S, Ruckenstein E : J. Appl. Polym. Sci., 38 453-461 (1989)

12) Yamaguchi $T$, Nakao $S$, Kimura $S$ : Macromolecules, 24 5522-5527 (1991)

13) Yamaguchi $T$, Nakao $S$, Kimura $S$ : Ind Eng. Chem. Res., 31 1914-1919 (1992)

14) Darkow $R$, Yoshikawa M, Kitao T, Tomaschewski G, Schellenberg J : J. Polym. Sci. : Part A : Polym. Chem., 32 1657-1664 (1994)

15) Tanihara N, Tanaka K, Kita H, Okamoto K : J. Membrane Sci., 95 161-169 (1994)

16) Park CK, Oh B-K, Choi MJ, Lee Y M : Polym. Bull., 33 591-598 (1994)

17) Sakohara S, Koshi T, Asaeda M : Kobunshi
Ronbunshu, 52 155-162 (1995)

18). Sun F, Ruckenstein E : J. Membrane Sci., 99 273-284 (1995)

19) Tanihara $N$, Umeo $N$, Kawabata $T$, Tanaka K, Kita H, Okamoto K : J. Membrane Sci., 104 181-192 (1995)

20) Yoshikawa M, Kitao T : Eur. Polym. J., 33 25-31 (1997)

21) Sakohara S, Koshi T : Kobunshi Ronbunshu, 54 115-118 (1997)

22) Yoshikawa M, Takeuchi S, Kitao T : Angew. Makromol. Chem., 245 193-202 (1997)

23) Inui $K$, Miyata $T$, Uragami $T$ : J. Polym. Sci. B : Polym. Phys., 35 699-707 (1997)

24) Yamasaki A, Shinbo T, Mizoguchi K : $J$. Appl. Polym. Sci., 64 1061-1065 (1997)

25) Hao J, Tanaka K, Kita H, Okamoto K : J. Membrane Sci., 132 97-108 (1997)

26) Inui $K$, Okamura $H$, Miyata $T$, Uragami $T$ : J. Membrane Sci., 132 193-202 (1997)

27) Yamada S : Maku (Membrane), 6 168-184 (1981)

28) Gmehling J, Onken U, Arlt W : Vapor-Liquid Equilibrium Data Collection, Vol. I, Part 6a, Behrens D, Wckermann R ed., DECHEMA, Frankfurt, 1980

29) "Polymer Handbook", 3rd edn., Brandrup J, Immergut G H ed., Wiley, New York (1989) (受付 1998 年 4 月 20 日 第三稿受付 10 月 5 日 掲載決定 10 月 13 日） 